\title{
Downregulation of P2Y2 and HuD during the development of the enteric nervous system in fetal rats with anorectal malformations
}

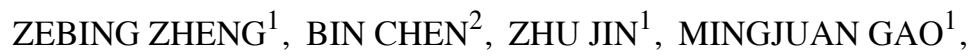

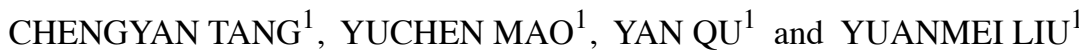

${ }^{1}$ Department of Pediatric, General Thoracic and Urinary Surgery, Affiliated Hospital of Zunyi Medical University, Zunyi, Guizhou 563000; ${ }^{2}$ Department of Surgery, Dezhou Union Hospital, Dezhou, Shandong 253000, P.R. China

Received October 16, 2018; Accepted May 17, 2019

DOI: $10.3892 / \mathrm{mmr} .2019 .10356$

\begin{abstract}
Certain patients with anorectal malformations (ARMs) continue to suffer from postoperative dysphoria. The enteric nervous system (ENS) is closely associated with defecation. The purinergic receptor P2Y2 (P2Y2) and Hu antigen D $(\mathrm{HuD})$ proteins contain multiple motifs that enable their activation and direct coupling to integrin and growth factor receptor signaling pathways; thus, they may serve as key points in ENS development. The aim of the present study was to investigate the expression pattern of $\mathrm{P} 2 \mathrm{Y} 2$ and $\mathrm{HuD}$ proteins during anorectal development in ARM embryos. The embryogenesis of ARM in rats was induced by ethylenethiourea (ETU) on the 10th gestational day. The expression patterns of P2Y2 and $\mathrm{HuD}$ proteins were evaluated by immunohistochemistry and western blot analysis in normal, ETU and ARM rat embryos on embryonic days E17, E19 and E21; their mRNA levels were assessed via reverse transcription-quantitative polymerase chain reaction (RT-qPCR) of the distal rectum of fetal rats. Immunohistochemistry of the distal rectum demonstrated that on E17, the expression levels of the two proteins were not different between the three groups. On E19, the expression of $\mathrm{HuD}$ was significantly decreased in the ARM group. On E21, the two proteins were significantly decreased in the ARM group. Additionally, the expression levels of the two proteins on E17 were significantly lower than on E21 in the ARM group. Western blotting and RT-qPCR also revealed that the P2Y2 and $\mathrm{HuD}$ proteins and mRNA expression levels were significantly decreased in the ARM groups when compared with the normal group on E17 and E21 $(\mathrm{P}<0.01)$. Thus, the present study demonstrated that downregulation of $\mathrm{P} 2 \mathrm{Y} 2$ and $\mathrm{HuD}$ may partly be related to the development of the ENS in ARM embryos.
\end{abstract}

Correspondence to: Dr Yuanmei Liu, Department of Pediatric, General Thoracic and Urinary Surgery, Affiliated Hospital of Zunyi Medical University, 149 Dalian Road, Zunyi, Guizhou 563000, P.R. China

E-mail: yuanmei116@aliyun.com

Key words: anorectal malformation, enteric nervous system, purinergic receptor $\mathrm{P} 2 \mathrm{Y} 2$, Hu antigen $\mathrm{D}$, development

\section{Introduction}

Anorectal malformations (ARMs) are frequently encountered anomalies that represent an important component of pediatric surgery practice. The incidence rate ranges from 1:1,500 to 1:5,000 live births (1). There also appears to be a wide spectrum of ARM epidemiology ranging from isolated cloacal, supralevator and infralevator anal atresia (with and without fistula) to ectopic anus malformation, and have variable clinical presentations ranging from mild forms that may require only minor surgical interventions to more complicated cases that require management with multi-staged operations $(2,3)$. Despite the continuous progression of ARM surgical treatments, certain patients still have anal dysfunctions following surgery, which seriously affects their quality of life (4). The cause of ARM is unknown, although arrest of the descent of the urorectal septum towards the cloacal membrane between the 4th and 8th weeks of gestation was previously considered the basic event leading to ARM (5). Since the molecular deteminants during blastogenesis are overlapping for many body systems, and these elements are closely related in timing and spacing, thus defects in blastogenesis often involve two or more progenitor fields (6). Several studies have reported on the mechanisms of enteric nervous system (ENS) development in embryos, and P2Y receptors have been revealed to primarily regulate muscle relaxation (7-10). Mulè et al (11), revealed that the $\mathrm{P} 2 \mathrm{Y}$ receptor antagonist suramin inhibited ATP-induced muscle relaxation, confirming that $\mathrm{P} 2 \mathrm{Y}$ receptors participate in muscle relaxation. P2Y receptor deficiency could lead to dysfunction in intestinal relaxation, resulting in intestinal spasticity (12). Our previous study indicated that purinergic receptor P2Y2 (P2Y2) may be one of the basic factors leading to ENS dysplasia at the end of the rectum of fetal rats with ARM in day 21 embryos (13). Another study demonstrated that P2Y2 is involved in the direct regulation of ENS, smooth muscle contractility and control of intestinal peristalsis (14).

Hu antigen $\mathrm{D}(\mathrm{HuD})$ is considered to be expressed specifically in neurons, while the other member of the Hu protein family, HuR, is ubiquitously expressed (15). Hu proteins have three RNA recognition motifs through which they associate with mRNAs bearing specific sequences that are often AUand U-rich. HuD binds to and stabilizes the 3'-untranslated 
region of target mRNAs, including $\mathrm{p} 21$, tau and GAP-43 mRNAs (15). HuD regulates the expression of neuron-specific genes and serves important roles in the growth, development and differentiation of neurons. It is a necessary protein for the formation and regeneration of nervous processes (16). It also modulates target mRNA translation. HuD demonstrates aberrant expression in diseased intestinal canals of children with Hischsprung's disease, which indicates that HuD has a close relationship with the development of the ENS (17). Our previous study revealed that the $\mathrm{HuD}$ protein is aberrantly expressed in the nerve plexuses of the intestinal wall of the terminal rectum of ARM embryonic 20-day rats, which suggests that $\mathrm{HuD}$ may participate in the development and maturation of the ENS in ARM embryonic rats (18). However, a previous study investigating different tissues unexpectedly observed HuD expression in ENS with ARMs (19); it was not clear whether P2Y2 and HuD continued to participate in the development of the ENS prior to the emergence of ARMs. To provide insights into the pattern of $\mathrm{P} 2 \mathrm{Y} 2$ expression and the possible role of HuD during ENS development, the present study examined the expression of P2Y2 and HuD in normal and ARMs model rat embryos at 17, 19 and 21 days.

\section{Materials and methods}

Animal model. A total of 120 Sprague Dawley (SD) rats at 10-12 weeks of age (210-260 g) were obtained from the Experimental Animal Center at the Daping Hospital of the Third Military Medical University (Chongqing, China). Ethical approval was obtained from the Zunyi Medical College Animal Ethics Committe (no. 20150820014) prior to the commencement of the study. Mating was performed at night with male and female rats at a 3 to 1 ratio. In the early morning, vaginal smears were obtained from female rats; if sperm or vaginal suppositories were discovered under a light microscope, it was recorded as embryonic day zero (E0). A total of 40 mated pregnant SD rats were randomly divided into the following two groups: Ethylenethiourea (ETU)-treated $(n=30)$ and normal groups $(n=10)$. The animals were maintained in a temperature-controlled environment $\left(20-24^{\circ} \mathrm{C}\right)$, a humidity of $50-70 \%$ and a 12-h light/dark cycle. Solid laboratory chow and water were available ad libitum. In the ETU-treated group, 30 pregnant rats were administered a single dose of $125 \mathrm{mg} / \mathrm{kg}$ of 1\% ETU (CAS no. 03940-I00G; Sigma-Aldrich; Merck $\mathrm{KGaA}$ ) by oral gavage on E10 to induce the ARM model (ARM group). Rats in the normal group were treated the same as the ETU group, however, they received corresponding doses of ETU-free saline on E10 instead of ETU. Embryos were harvested by cesarean delivery at E17, E19 and E21. The presence of ARMs was determined by light microscope. Then, the embryos were divided into normal, ETU and ARM groups.

Tissue handling. The pregnant rats were anesthetized with chloral hydrate by intraperitoneal injection $(0.3 \mathrm{ml} / 100 \mathrm{~g}$ body weight; Sinopharm Chemical Reagent Co., Ltd.). The uterine horn was incised through the abdominal wall. Embryos were obtained by cesarean section on E17, E19 and E21. Subsequently, pregnant rats were sacrificed with an excessive dose of sodium pentobarbital. The embryos were then divided into the normal, ETU (therapeutic rats that exhibited no deformities) and ARM groups. One-third of the embryos, based on their weight, were fixed in $4 \%$ paraformaldehyde for 12 to $24 \mathrm{~h}$. Then the embryos of all age groups were dehydrated and embedded in paraffin. Immunohistochemical staining was performed on serial and sagittal sections of up to 4- $\mu \mathrm{m}$ thickness. The presence of ARMs was determined under a light microscope. Under a magnifying glass, the distal rectum of the remaining two-thirds of the embryos was dissected and removed from the surrounding tissues. The distal rectum was immediately frozen in liquid nitrogen for western blot analysis and reverse transcription-quantitative polymerase chain reaction (RT-qPCR).

Hematoxylinandeosin $(H \& E)$ staining. The paraffin-embedded terminal rectum tissues were consecutively cut to a thickness of $3 \mu \mathrm{m}$. Following conventional H\&E staining, the structure of the distal rectum, and the number and morphology of the intermuscular and submucosal nervous plexus of the distal rectum were observed under an optical microscope.

Immunohistochemistry. Immunohistochemical staining was performed as previously described $(9,13)$. Sections were incubated overnight at $4^{\circ} \mathrm{C}$ with the primary rabbit anti-mouse P2Y2 (1:125; cat. no. sc-518091) and mouse anti-rat HuD (1:80; cat. no. sc-28299; both from Santa Cruz Biotechnology, Inc.) polyclonal antibodies. Following primary antibody incubation, the sections were washed and incubated with biotinylated goat anti-rabbit secondary antibody A (cat. no. A0456; dilution $2 \mu \mathrm{g} / \mathrm{l}$; ZSGB-BIO; OriGene Technologies, Inc.) for $20 \mathrm{~min}$ at room temperature. Following incubation, the sections were incubated with reagent B (ZSGB-BIO; OriGene Technologies, Inc.) for $30 \mathrm{~min}$ at room temperature. Immunoreactivity was visualized under an ordinary light microscope following the addition of 3'3-diaminobenzidine (ZSGB-BIO; OriGene Technologies, Inc.) and the chromogenic degree was observed to subsequently adjust the incubation time. Sections were stained with hematoxylin for $3 \mathrm{sec}$ at room temperature. Negative controls received PBS instead of primary antibodies. Human cerebral cortex tissues from tissue bank (cat. no. 201324; Research Center for Medical \& Biology Tissue Bank, Zunyi Medical University) were used for the P2Y2 positive control, while human breast tissue (cat. no. 201324; Research Center for Medical \& Biology Tissue Bank; Zunyi Medical University) was used for the HuD positive control. All sections were photographed using an optical microscope (magnification, $\mathrm{x} 400$ ). The target images were collected and compiled with the Leica QWin image analysis system. The integral optical density was calculated using Image Pro Plus 6 image analysis software (Media Cybernetics, Inc.).

Protein preparation and western blot analysis. Protein preparation was performed as previously described (20). Total protein was extracted from the distal rectum collected from the normal, ETU and ARM groups on days E17, E19 and E21, and frozen at $-80^{\circ} \mathrm{C}$. The Enhanced Bicinchoninic Acid Protein Assay kit (Beyotime Institute of Biotechnology) was used for protein quantification according to the manufacturer's protocol. Protein extracts (50 $\mu \mathrm{g} /$ lane) were mixed with $5 \mathrm{X}$ SDS-PAGE (Beyotime Institute of Biotechnology) loading buffer (40 $\mu \mathrm{l})$, heated at $90^{\circ} \mathrm{C}$ for $5 \mathrm{~min}$, transferred to polyvinylidene fluoride 
Table I. Distribution of embryos in the various age and treatment groups.

\begin{tabular}{|c|c|c|c|c|c|c|c|c|c|c|c|c|}
\hline \multirow[b]{2}{*}{$\mathrm{E}(\mathrm{d}) /$ group } & \multicolumn{4}{|c|}{ Normal } & \multicolumn{4}{|c|}{ ETU } & \multicolumn{4}{|c|}{ ARM } \\
\hline & $\mathrm{H} \& \mathrm{E}$ & IHC & WB & PCR & $\mathrm{H} \& \mathrm{E}$ & IHC & WB & PCR & $H \& E$ & IHC & WB & PCR \\
\hline 17 & 7 & 7 & 7 & 7 & 7 & 7 & 7 & 7 & 7 & 7 & 7 & 7 \\
\hline 19 & 7 & 7 & 7 & 7 & 7 & 7 & 7 & 7 & 7 & 7 & 7 & 7 \\
\hline 21 & 7 & 7 & 7 & 7 & 7 & 7 & 7 & 7 & 7 & 7 & 7 & 7 \\
\hline Total & 21 & 21 & 21 & 21 & 21 & 21 & 21 & 21 & 21 & 21 & 21 & 21 \\
\hline
\end{tabular}

E, embryonic; ETU, ethylenethiourea; ARM, anorectal malformations; H\&E, hematoxylin and eosin; IHC, immunohistochemical; WB, western blotting; PCR, real-time PCR.

membranes and blocked with $5 \%$ fat-free milk in Tris-buffered saline for $3 \mathrm{~h}$ at room temperature. Membranes were incubated with primary rabbit anti-mouse antibodies against P2Y2 (1:400; cat. no. sc-518091; Santa Cruz Biotechnology, Inc.) and primary mouse anti-rat antibodies against $\operatorname{HuD}(1: 200$; cat. no. sc-28299; Santa Cruz Biotechnology, Inc.), and $\beta$-actin (1:400; mouse monoclonal; cat. no. 610154; Wuhan Boster Biological Technology, Ltd.). The membranes were subsequently incubated with horseradish peroxidase-conjugated secondary antibodies anti-mouse (1:4,000; cat. no. sc-516102; Santa Cruz Biotechnology, Inc.) or anti-rabbit (1:6,000; cat. no. sc-2357; Santa Cruz Biotechnology, Inc.) for $2 \mathrm{~h}$ at room temperature. The membranes were developed using an ECL substrate kit (cat. no. tf-2012215; Pierce; Thermo Fisher Scientific, Inc.) and densitometric values were analyzed using the Enhance Chemiluminescence Plus detection system (EMD Millipore). Protein levels were normalized to $\beta$-actin.

$R N A$ isolation and $R T-q P C R$. Total RNA was isolated from the rat distal rectum of the normal, ETU and ARM groups using RNAiso Plus (TRIzol; Takara Biotechnology Co., Ltd.), following the manufacturer's instructions. The A260/A280 OD value of the total RNA ranged from 1.8 to 2.0. The extracted RNA was diluted to a concentration of $1 \mu \mathrm{g} / \mu \mathrm{l}$, and its equivalents were stored at $-80^{\circ} \mathrm{C}$. Single-strand cDNA was reverse transcribed with the PrimeScript RT Reagent kit (Takara Biotechnology Co., Ltd.). Primers used for RT-qPCR included the following: P2Y2 forward 5'-TGCTCTACTTTGTCACCA CCA-3' and reverse, 5'-CTTGTCATCCCGTCAATGG-3'; HuD forward, 5'-ACCAGGCTCAAAGATTCAGG-3' and reverse, 5'-CTTGTCATCCCGTCAATGG-3'; and $\beta$-actin (used as an endogenous control) forward, 5'-GGAGATTAC TGCCCTGGCTCCTA-3' and reverse, 5'-GACTCATCGTAC TCCTGCTTGCTG-3'. RT-qPCR was conducted with SYBR Premix Ex Tap (cat. no. DRR081S; Takara Biotechnology Co., Ltd.) on a 7900HT fast real-time PCR system (Applied Biosystems; Thermo Fisher Scientific, Inc.) under the following thermocycling conditions: $50^{\circ} \mathrm{C}$ for $2 \mathrm{~min}, 95^{\circ} \mathrm{C}$ for $10 \mathrm{~min}$, followed by 40 cycles at $95^{\circ} \mathrm{C}$ for $15 \mathrm{sec}$ and $60^{\circ} \mathrm{C}$ for $60 \mathrm{sec}$. The results of qPCR were analyzed with LightCycler 1.5 System software (Roche Diagnostics $\mathrm{GmbH}$ ). Melting curves were generated during the dissociation process to determine the specificity of the amplification. Relative levels of gene expression were determined as $\Delta \mathrm{Cq}=(\mathrm{Cq}$ gene $)-(\mathrm{Cq}$ reference $)$, and the fold change in gene expression was calculated using the $2^{-\Delta \Delta \mathrm{Cq}}$ method (21).

Statistical analysis. SPSS version 16.0 (SPSS Inc.) was used for statistical analyses. The data are consistent with normal distribution, with homogeneity of variance and one-way analysis of variance and Tukey's post hoc test used to analyze the levels of P2Y2 and HuD expression between the normal, ETU and ARM model rat groups. All results were expressed as the mean \pm standard deviation, and $\mathrm{P}<0.05$ was considered to indicate a statistically significant difference.

\section{Results}

General observation. In the present study, no anomalies were identified in the 142 normal model rat embryos examined. A total of 104 ETU-treated fetal rats were normal and 146 ARM model rat embryos were obtained from the 256 ETU-treated rat embryos. All rats produced from ETU-treated embryos exhibited a short or no tail, and 6 perished during the Cesarean section. Spinal bifida and/or meningocele were also observed externally. The incidence of ARMs (manifesting as rectourethral fistula or common cloaca) in ETU-treated embryos from E17 to E21 was $57.3 \%$. The anal opening position was normal in the control and ETU groups, and the anal opening was a closed blind end in the ARM group (Table I).

$H \& E$ staining. At E17, the nerve plexus count in the submucousal and intermuscular clusters was not different between the three groups (Fig. 1). On E19, the nerve plexus count in the ARM group was greater than that at E17 ( $\mathrm{P}<0.05$; Fig. 1). On E21, the nerve plexus count in the ETU group was significantly increased compared with that at E19 (P<0.01; Fig. 1). There was decreased development of the distal rectum nerve plexus count in the E19 and E21 ARM groups compared with the normal and ETU groups. Within the ARM group, the nerve plexus count was significantly different between the E17 and E19 embryos ( $\mathrm{P}<0.01 ;$ Fig. 1).

Immunohistochemical results. P2Y2 and $\mathrm{HuD}$ were mainly expressed in the distal submucosa and intermuscular plexus of the fetal rats, and were primarily expressed in the cytoplasm. There was a small amount of $\mathrm{HuD}$ expression in the nucleus. As the embryo developed, the color corresponding to 
Table II. Expression of P2Y2-positive rate at the distal rectum in the three groups.

\begin{tabular}{lccccccc}
\hline & \multicolumn{5}{c}{ Normal group/ETU group/ARM group $(\mathrm{n}=10)$} & & \\
\cline { 2 - 5 } $\mathrm{E}(\mathrm{d})$ & - & + & ++ & +++ & Total & Negative rate $(\%)$ & Strong-positive rate (\%) \\
\hline 17 & $2 / 3 / 3$ & $8 / 7 / 7$ & $0 / 0 / 0$ & $0 / 0 / 0$ & $10 / 10 / 10$ & $20 / 30 / 30$ & $0 / 0 / 0$ \\
19 & $0 / 0 / 3$ & $7 / 6 / 6$ & $3 / 4 / 1$ & $0 / 0 / 0$ & $10 / 10 / 10$ & $0 / 0 / 30$ & $0 / 0 / 0$ \\
21 & $0 / 0 / 1$ & $2 / 3 / 7$ & $3 / 3 / 1$ & $5 / 4 / 1$ & $10 / 10 / 10$ & $0 / 0 / 10$ & $50 / 40 / 10$ \\
\hline
\end{tabular}

(-): negative staining; (+): weakly-positive staining, stained yellowish; $(++$ and +++$)$ : positive staining to strong-positive staining, stained yellowish brown to yellow brown. ETU, ethylenethiourea; ARM, anorectal malformations.

Table III. Expression of $\mathrm{HuD}$ positive rate at the distal rectum in the three groups.

\begin{tabular}{|c|c|c|c|c|c|c|c|}
\hline \multirow[b]{2}{*}{$\mathrm{E}(\mathrm{d})$} & \multicolumn{5}{|c|}{ Normal group/ETU group/ARM group $(n=10)$} & \multirow[b]{2}{*}{ Negative rate $(\%)$} & \multirow[b]{2}{*}{ Strong-positive rate $(\%)$} \\
\hline & - & + & ++ & +++ & Total & & \\
\hline 17 & $2 / 3 / 4$ & $8 / 7 / 6$ & $0 / 0 / 0$ & $0 / 0 / 0$ & $10 / 10 / 10$ & $20 / 30 / 40$ & $0 / 0 / 0$ \\
\hline 19 & $0 / 0 / 2$ & $8 / 8 / 6$ & $2 / 2 / 2$ & $0 / 0 / 0$ & $10 / 10 / 10$ & $0 / 0 / 20$ & $0 / 0 / 0$ \\
\hline 21 & $0 / 0 / 0$ & $1 / 2 / 7$ & $5 / 4 / 2$ & $4 / 4 / 1$ & $10 / 10 / 10$ & $0 / 0 / 0$ & $40 / 40 / 10$ \\
\hline
\end{tabular}

(-): negative staining; $(+)$ : weakly positive staining, stained yellowish; $(++$ and +++$)$ : positive staining to strong-positive staining, stained yellowish brown to yellow brown. ETU, ethylenethiourea; ARM, anorectal malformations.

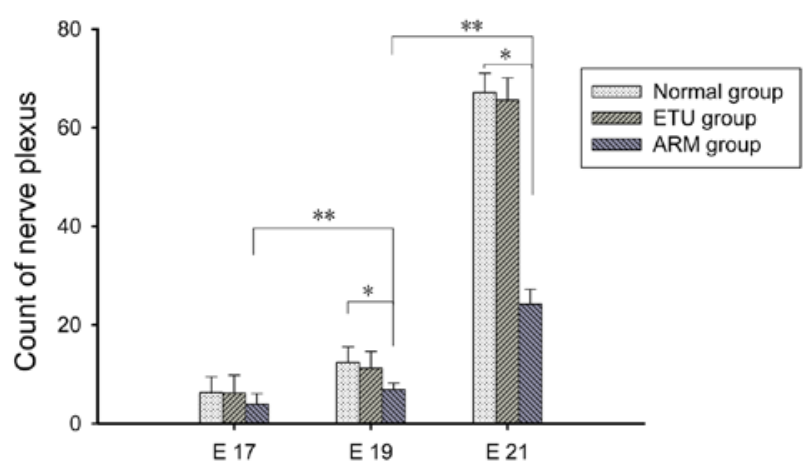

Figure 1. Hematoxyling and eosin staining analysis of nerve plexus count. At E17, the nerve plexus count in the submucousal and intermuscular clusters was not different among the three groups. At E19, the nerve plexus count in the ARM group was increased compared with E17. At E21, the intermuscular and submucosal nerve plexus count between the normal and ETU group was significantly increased compared with E19. There was a decreased nerve plexus count in the ARM group at E19 and E21 compared with the normal group. Within the ARM group, there was a significant difference in the nerve plexus count between the E17 and E19 embryos. Data are expressed as the mean \pm SD. ${ }^{*} \mathrm{P}<0.05 ;{ }^{* *} \mathrm{P}<0.01$. ETU, ethylenethiourea; ARM, anorectal malformations.

protein expression changed from yellowish to yellowish brown to yellow brown; the range of expression also increased. At E21, the expression of P2Y2 strong-positive rate was 50\% in the normal group, $40 \%$ in the ETU group, and $10 \%$ in the ARM group; the expression of HuD strong-positive rate was $40 \%$ in the normal group, $40 \%$ in the ETU group, $10 \%$ in the ARM group. The nerve plexus in the ARM group was small compared with the normal and ETU groups (Tables II and III).
P2Y2 protein quantitative analysis. On E17, a small amount of P2Y2 protein with yellowish staining was observed at the distal rectum of the three groups. Respectively 8, 7, and 7 cases in the normal, ETU and ARM groups were observed with weak-positive staining. The expression of $\mathrm{P} 2 \mathrm{Y} 2$ was low, and there was no significant difference between the three groups $(P>0.05)$. At E19, the normal and ETU groups were stained yellowish, while some areas appeared yellowish brown. Respectively 7, 6, and 6 cases in the normal, ETU and ARM groups were observed with weak-positive staining; and 3, 4, 1 cases in the normal, ETU and ARM groups, respectively, were observed with positive staining. The degree of staining increased in intensity when compared with the staining in E17, however the expression was still low; there was no difference between the three groups. At E21, the distal rectum in the normal and ETU groups appeared yellowish brown or dark brown, with a marked increase in intensity; yellow staining could be clearly observed in the intermuscular and mucous membrane. Respectively 2, 3, and 7 cases in the normal, ETU and ARM groups were observed with weak-positive staining; 3, 3, and 1 in the normal, ETU and ARM groups respectively, were observed with positive staining; and 5, 4, and 1 in the normal,ETU and ARM groups, respectively, were observed with strong-positive staining. There was a significant difference between the E21 and E19 embryos $(\mathrm{P}<0.01)$. The expression reported in the ARM group was significantly lower than that of the normal group $(\mathrm{P}<0.01)$. There was no significant difference between the E17 and E19 ARM groups, while a significant increase in expression was observed in the E21 ARM group when compared with the E17 ARM group $(\mathrm{P}<0.01$; Figs. 2A and 3). 

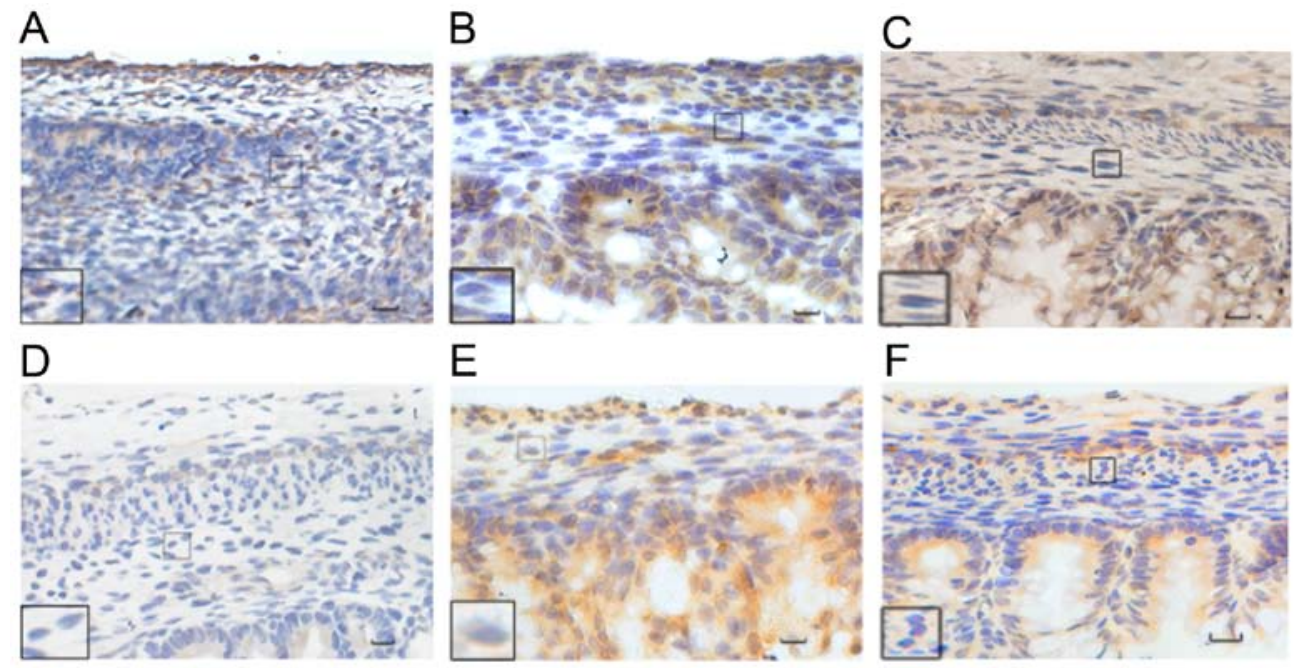

G
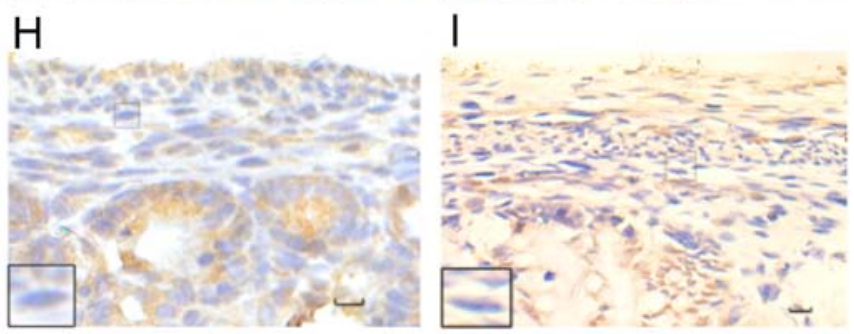

Figure 4. Immunohistochemical analysis of HuD protein. The normal group at (A) E17, (B) E19, and (C) E21. The ETU group at (D) E17, (E) E19, (F) E21. The ARM group at (G) E17, (H) E19, (I) E21. HuD was mainly expressed in the cytoplasm, with a small amount observed in the nucleus, and in the distal submucosa and intermuscular plexus of the fetal rat. The color of the expressed proteins changed from yellowish to yellowish brown to yellow brown as the embryo developed, with an increase in the range of expression also observed. Black rectangles reveal images at a higher magnification. Scale bar, $25 \mu \mathrm{m}$; magnification, x400. HuD, Hu antigen D; ETU, ethylenethiourea. ARM, anorectal malformations.

A

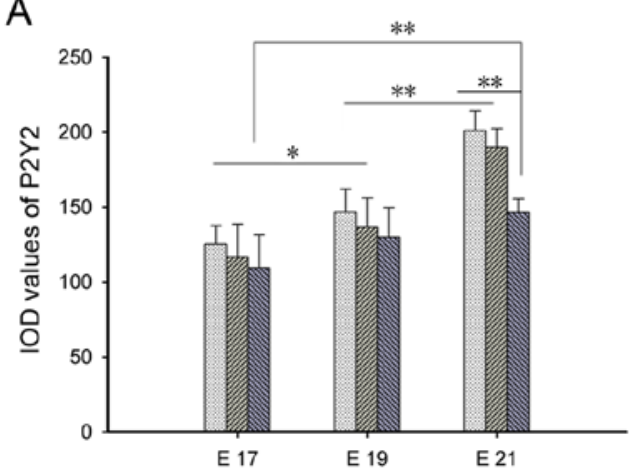

B

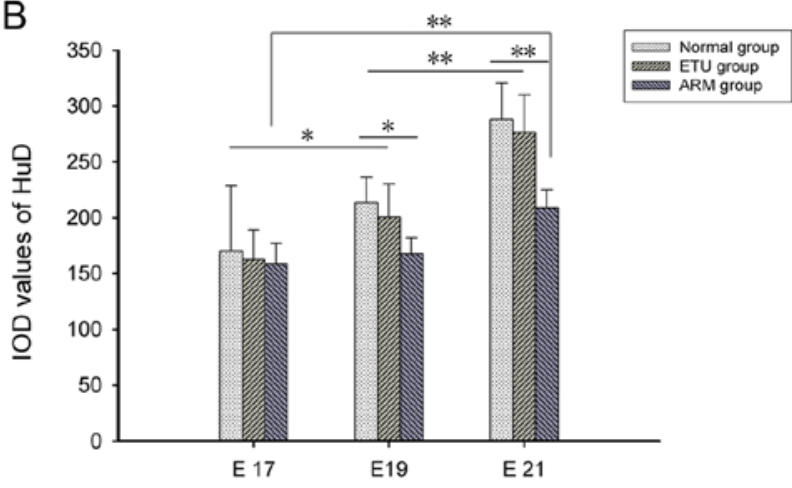

Figure 2. Immunohistochemical analysis of P2Y2 and HuD protein expression levels in the normal, ETU and ARM fetal rat groups. (A and B) Histogram revealing the trends in $\mathrm{P} 2 \mathrm{Y} 2$ and $\mathrm{HuD}$ expression at each time-point. P2Y2 and HuD protein expression increased gradually over time in the three groups; the levels of HuD protein expression were significantly lower in the distal rectum from the ARM model rats at E19 and E21 when compared with the other groups. However, the levels of P2Y2 protein expression were significantly lower in the distal rectum from ARM model rats at E21 when compared with the other groups. Data are presented as the mean \pm standard deviation (analyzed by one-way analysis of variance test). $\mathrm{P}<0.05,{ }^{* *} \mathrm{P}<0.01$. IOD, Integral optical Density; ETU, ethylenethiourea; ARM, anorectal malformations; P2Y2, purinergic receptor P2Y2; HuD, Hu antigen D.

$H u D$ protein quantitative analysis. At E17, respectively 8, 7, and 6 cases in the normal, ETU and ARM groups were observed with weak-positive staining, a small amount of HuD protein with yellowish staining was observed at the distal rectum and there was no significant difference between the three groups $(\mathrm{P}>0.05)$. At E19, respectively 8, 8, and 6 cases in the normal, ETU and ARM groups were observed with weak-positive staining; and 2, 2, and 2 in the normal, ETU and ARM groups, respectively, were observed with positive staining. The normal and ETU groups were stained yellowish and brown in some areas, which was more pronounced than at E17 $(\mathrm{P}<0.01)$. At E21, respectively 1,2 , and 7 case(s) in the normal, ETU and ARM groups were observed with weak-positive staining; 5, 4, and 2 in the normal, ETU and ARM groups, respectively, were observed with positive staining; and 4, 4, and 1 in the normal, ETU and ARM groups, respectively, were observed with strong-positive staining. The distal rectum was stained yellowish brown or dark brown in the normal and ETU groups, with a marked increase in expression. 

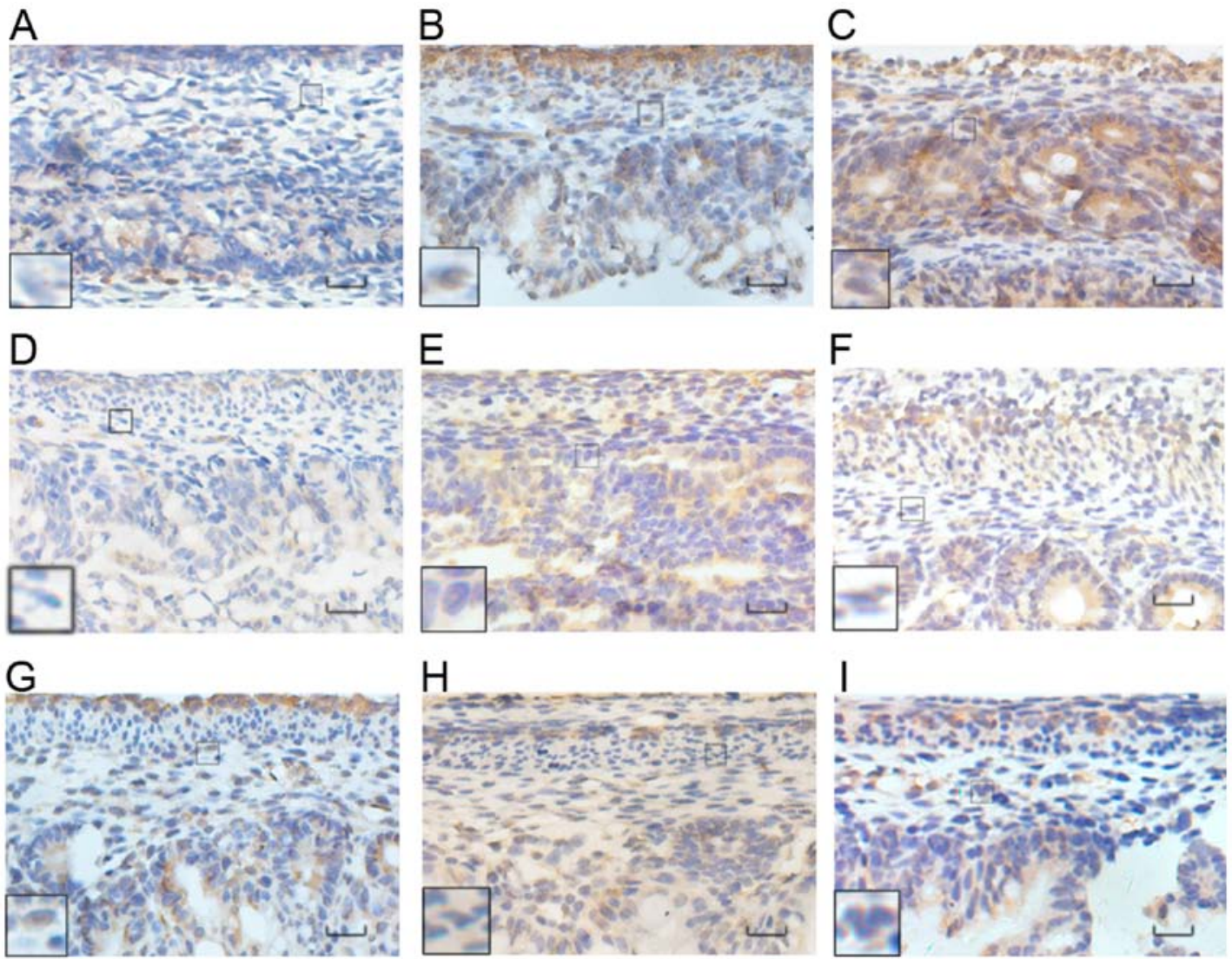

Figure 3. Immunohistochemical analysis of P2Y2 protein. The normal group at (A) E17, (B) E19 and (C) E21. The ETU group at (D) E17, (E) E19 and (F) E21 The ARM group at (G) E17, (H) E19 and (I) E21. P2Y2 was mainly expressed in the cytoplasm and in the distal submucosa and intermuscular plexus of the fetal rat. The color of the expressed proteins changed from yellowish to yellowish brown to yellow brown as the embryo developed, and an increase in the range of expression was also observed. Black rectangles reveal images at a higher magnification. Scale bar, $25 \mu \mathrm{m}$; magnification, $\mathrm{x} 400$. P2Y2, purinergic receptor P2Y2; ETU, ethylenethiourea; ARM, anorectal malformations.

The yellow dye could be clearly observed between the muscles and the mucosa, and there was a significant difference between the E21 and E19 embryos $(\mathrm{P}<0.01)$. The HuD expression level in the ARM group was significantly decreased when compared with the normal group $(\mathrm{P}<0.01)$; the expression increased with the development of the embryo in the ARM group. There was no significant difference between the E17 and the E19 ARM groups; however, the expression level of the E21 ARM group was significantly higher than the E17 ARM group ( $\mathrm{P}<0.01$; Figs. 2B and 4).

Western blot analysis. The expression levels of the P2Y2 and $\mathrm{HuD}$ proteins were evaluated by western blot analysis during ENS development in the normal, ETU and ARM group model rats. $\mathrm{P} 2 \mathrm{Y} 2$ and $\mathrm{HuD}$ bands were normalized to the corresponding $\beta$-actin band. The expression of P2Y2 and HuD proteins increased with time in the three groups. Significantly decreased $\mathrm{HuD}$ expression was detected in the distal rectum of the ARM group at E19 and E21 when compared with the other groups $(\mathrm{P}<0.05)$; in addition, the decreased expression of $\mathrm{P} 2 \mathrm{Y} 2$ protein was detected in the distal rectum of ARM model rats at E21 when compared with the other groups $(\mathrm{P}<0.05$; Fig. 5).

RT-qPCR analysis. The expression levels of P2Y2 and HuD mRNA were normalized to $\beta$-actin in the same specimen. The results obtained were consistent with those of western blotting; the expression levels of P2Y2 and HuD mRNA increased with time in the normal and ARM groups. Subsequently, the expression levels of $\mathrm{P} 2 \mathrm{Y} 2 \mathrm{mRNA}$ in the distal rectum of the ARM model rats at E21 were significantly lower than those of the other groups $(\mathrm{P}<0.05)$, while the levels of $\mathrm{HuD}$ protein in the distal rectum of the ARM group at E19 and E21 were significantly lower when compared with the other groups $(\mathrm{P}<0.05$; Fig. 6).

\section{Discussion}

ARMs represent a wide spectrum of defects and are some of the most common digestive tract anomalies encountered in pediatric surgery. In the past, many surgical techniques to repair ARM have been described. These included endorectal dissection (1-3), an anterior perineal approach to a rectourethral fistula (4), and many different types of anoplasties. However, children with ARMs often have more complications at the postoperative stage, including constipation, diarrhea and feces incontinence, which seriously affect patient quality of life following surgery (4). At present, the key to addressing this disease is to devise a treatment method to reduce postoperative complications. A previous study has revealed that ARMs are often accompanied by ENS dysplasia (22). When the ENS is absent (aganglionosis) or defective, children may develop constipation, vomiting, abdominal pain and growth failure, and some may even perish $(23,24)$. However, whether P2Y2 
A

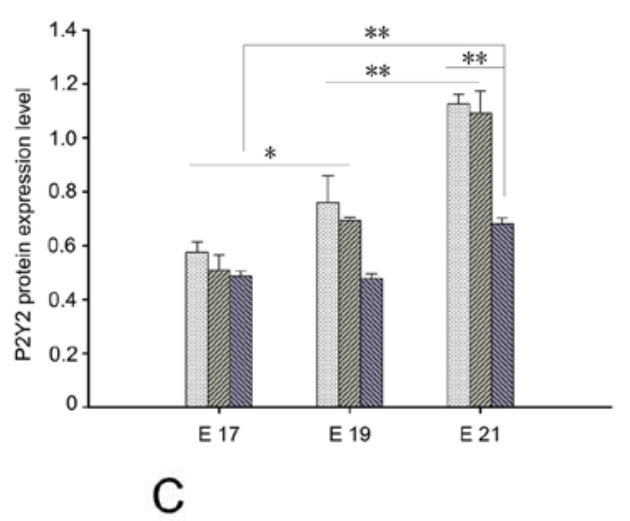

B

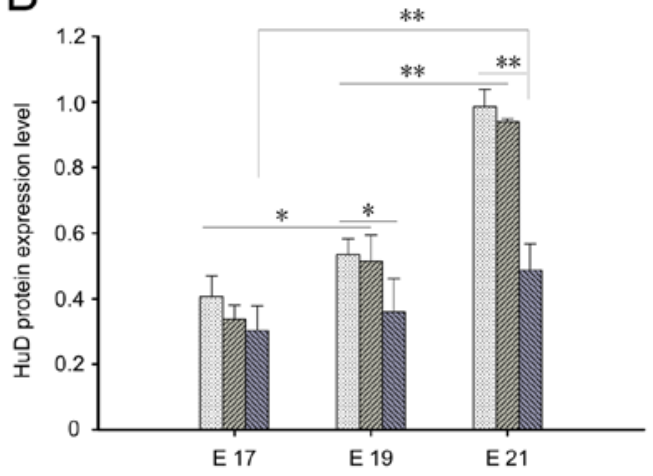

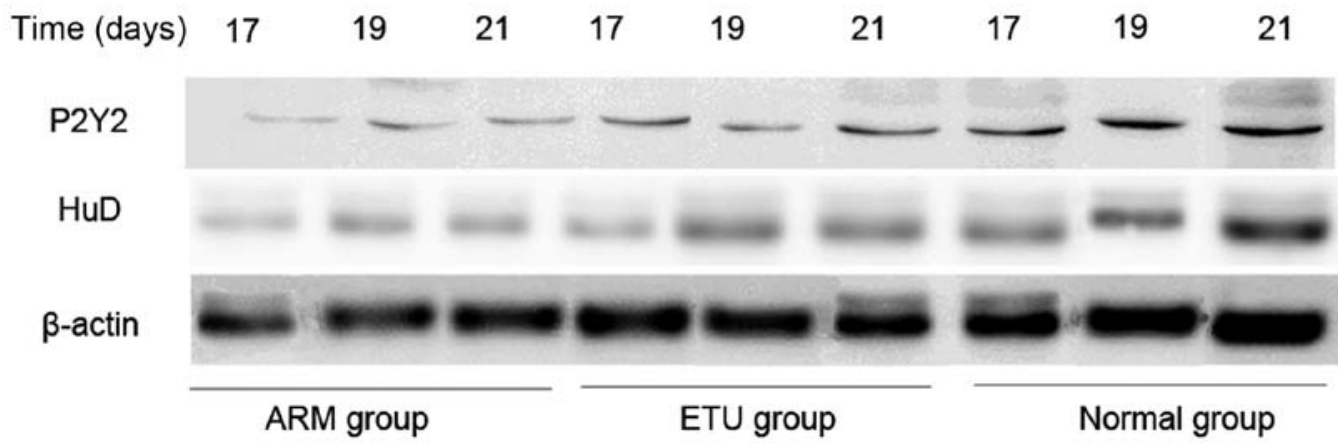

Figure 5. Western blot analysis of P2Y2 and HuD protein expression levels in the normal, ETU and ARM fetal rat groups. (A and B) Histogram revealing the trends of P2Y2 and HuD expression at each time-point. P2Y2 and HuD protein expression gradually increased over time in the three groups, with the levels of $\mathrm{HuD}$ protein expression significantly lower in the distal rectum from the ARM model rats at E19 and E21 compared with the other groups. However, the levels of P2Y2 protein were significantly lower in the distal rectum from ARM model rats at E21 when compared with other groups. Data are presented as the mean \pm standard deviation (analyzed by one-way analysis of variance test). ${ }^{*} \mathrm{P}<0.05,{ }^{* *} \mathrm{P}<0.01$. (C) $\mathrm{P} 2 \mathrm{Y} 2$ and HuD were detected with bands of $\sim 25$ and $50 \mathrm{kDa}$, respectively; $\beta$-actin protein was used as an internal control. Expression levels were detected by western blot analysis. P2Y2, purinergic receptor P2Y2; HuD, Hu antigen D; ETU, ethylenethiourea; ARM, anorectal malformations.

A

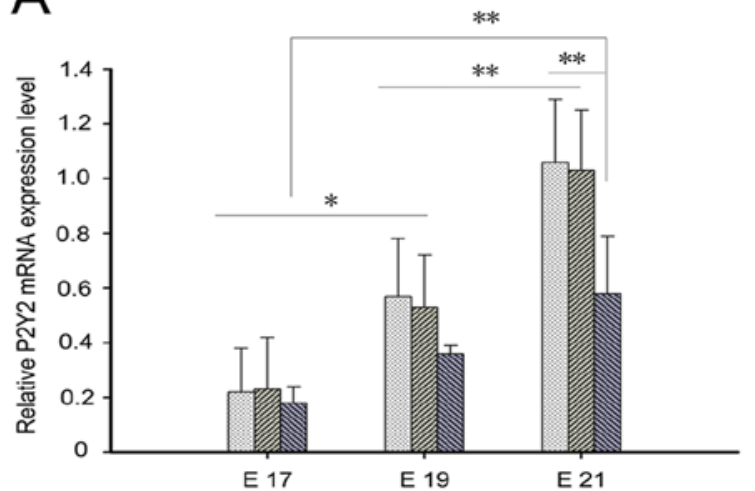

B

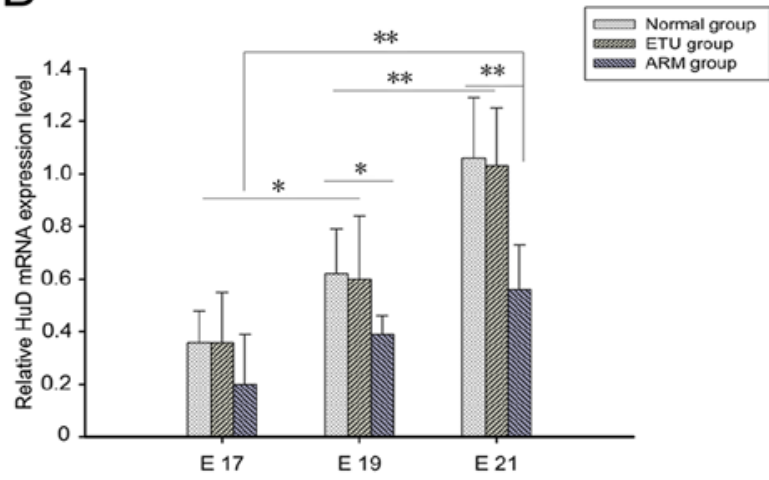

Figure 6. Reverse transcription-quantitative polymerase chain reaction analysis of P2Y2 and HuD mRNA expression levels in the normal, ETU and ARM fetal rat groups. (A and B) Histogram presenting the trends of P2Y2 and HuD expression at each time-point. P2Y2 and HuD mRNA expression gradually increased over time in the three groups. The levels of HuD mRNA expression were significantly lower in the distal rectum from ARM model rats at E19 and E21 when compared with the other groups, but the levels of P2Y2 mRNA expression were significantly lower in the distal rectum from ARM model rats at E21 when compared with other groups. Data are presented as the mean \pm standard deviation (analyzed by one-way analysis of variance test). ${ }^{*} \mathrm{P}<0.05,{ }^{* *} \mathrm{P}<0.01$. $\mathrm{P} 2 \mathrm{Y} 2$, purinergic receptor P2Y2; HuD, Hu antigen D; ETU, ethylenethiourea; ARM, anorectal malformations.

and $\mathrm{HuD}$ have parallel developments with the ENS of ARMs remains to be clarified $(25,26)$. The present study was designed to investigate the potential role of P2Y2 and HuD during ENS development by examining the expression patterns of P2Y2 and HuD mRNA and protein in normal and ARM model rats at different embryonic developmental stages.
P2Y receptors (P2YRs) are typical 7-channel transmembrane receptors and are heterotrimeric $G$ proteincoupled $(27,28)$. Activation of P2Y2R by ATP or UTP can induce the phosphorylation of growth factor receptors $(29,30)$, which increases the activities of the mitogen-activated protein kinases, extracellular signal-regulated kinase-1/2 and the 
associated adhesion focal tyrosine kinase; these go on to regulate the ENS or directly regulate the contractility of intestinal smooth muscle to control intestinal peristalsis $(31,32)$. In our previous study, the glial cell factor, glial cell-derived neurotrophic factor and its signal receptor RET had an effect on the development of the ENS (10). Wullaert et al (32) used upstream agonists and inhibitors to control the purine receptor. It was revealed that ATP could promote axonal growth through the P2Y2 receptor (33). In addition, Arthur et al (12) also demonstrated that ATP activates the G protein-coupled receptor following activation $\mathrm{P} 2 \mathrm{Y} 2$, which acts on the regionalization and association of tyrosine receptor A and P2Y2 receptors, promoting the growth, differentiation and migration of neurons. In addition, the endogenous ATP, which is used for the first time in the human intestinal tract, acts on the P2Y receptor located in the intestinal smooth muscle and regulates intestinal relaxation; this effect can be blocked by P2YR (34). By combining the aforementioned results with our own previous research, it appears that there is a difference between the P2Y2 receptor and the distal end of the rectum in ARMs and normal fetal rats. It was suggested that P2Y2 may partly be related to the development of the intestinal nervous system.

$\mathrm{HuD}$ has been revealed to promote neuronal differentiation and axonal outgrowth in neurons in culture and in vivo (15). $\mathrm{HuD}$ can be used as a supplement to P2Y2 for the accurate counting of intestinal neurons and analysis of neuron types. In a study that used an anti-Hu antibody, anti-PGP9.5 and anti-neuron specific enolase for triple staining in cultured intestinal neurons, HuD protein was markedly expressed on all of the neurons in the intramuscular clusters of the small intestine, indicating that $\mathrm{HuD}$ has distinct specificity (35). The expression of $\mathrm{HuD}$ in Hirschsprung disease was significantly lower than in the normal segment $(36,37)$. However, there are few reports of $\mathrm{HuD}$ in ARM-associated diseases.

The present experimental study revealed that at E17, normal fetal rats had completely ruptured the anal membrane to form the anus, while the ETU malformation group did not form an anus, had developed multiple deformities and the development of the nerve plexus was poor. P2Y2 and HuD were mainly expressed in the distal submucosa and intermuscular plexus of the fetal rat and were primarily expressed in the cytoplasm. The expression of P2Y2 and HuD in the rectum was lower, and there was no difference in the three groups at E17. These results indicated that there was a relative imbalance in expression between the normal and ARM model embryos during ENS development. While ETU can cause ARMs in embryos, it had no marked effect on the expression of P2Y2 and HuD. At E21, the expression levels of P2Y2 and HuD in the ETU group were significantly lower than the ARM group, suggesting that P2Y2 and HuD may be responsible for the abnormal development of the ENS. The changes in these two microenvironmental factors hindered the development and migration of the intestinal nervous system. The expression of P2Y2 and HuD from E17 to E19 changed more slowly than that observed between E19 to E21. It has been suggested that E19 is the critical period of ENS formation.

In conclusion, the results from the present study, and those of previous studies, suggested that the downregulation pattern of P2Y2 and HuD may be important for ENS development in the anorectum of fetal rats with ETU-induced ARMs. Since many signaling molecules have been revealed to be expressed and function differently during different phases of ENS development, the present study was unable to determine whether P2Y2 and HuD were the primary factors that led to ENS anomalies. Further studies are required to define the two signaling molecules that are involved in regulating ENS formation during embryonic development and to clarify the specific roles of molecular mechanisms mediating the maldevelopment of the ENS, and thus help to improve our understanding of postoperative defecation disorder and patient quality of life.

\section{Acknowledgements}

Not applicable.

\section{Funding}

The present study was supported by the National Natural Science Fund of China (grant no. 81650029).

\section{Availability data and materials}

The datasets used and/or analyzed during the present study are available from the corresponding author on reasonable request.

\section{Authors' contributions}

$\mathrm{ZZ}$ and $\mathrm{BC}$ performed the majority of experiments, contributed equally to the work, authored or reviewed drafts of the paper, and approved the final draft. ZJ performed the experiments, authored or reviewed drafts of the paper, and approved the final draft. MG, CT, YM, and YQ analyzed the data, authored or reviewed drafts of the paper, and approved the final draft. YL conceived and designed the experiments, contributed the reagents/materials/analysis tools, authored or reviewed drafts of the paper, and approved the final draft and all authors agree to be accountable for all aspects of the research in ensuring that the accuracy or integrity of any part of the work are appropriately investigated and resolved.

\section{Ethics approval and consent to participate}

Ethical approval was obtained from the Zunyi Medical College Animal Ethics Committee (no. 20150820014). Animal care and handling procedures for ex vivo studies performed in China were as per the protocol approved by the Institutional Animal Care and Use Committee of Zunyi Medical College. Animal handling procedures for in vivo studies conducted in China were approved by the Institutional Animal Care and Use Local Committee.

\section{Patient consent for publication}

Not applicable.

\section{Competing interests}

The authors declare that they have no competing interests. 


\section{References}

1. Peña A, Guardino K, Tovilla JM, Levitt MA, Rodriguez G and Torres R: Bowel management for fecal incontinence in patients with anorectal malformations. J Pediatr Surg 33: 133-137, 1998.

2. Levitt MA and Peña A: Outcomes from the correction of anorectal malformations. Curr Opin Pediatr 17: 394-401, 2005.

3. Sonnino RE, Reinberg O, Bensoussan AL, Laberge JM and Blanchard $\mathrm{H}$ : Gracilis muscle transposition for anal incontinence in children: Long-term follow-up. J Pediatr Surg 26: 1219-1223, 1991.

4. Bai Y, Yuan Z, Wang W, Zhao Y, Wang H and Wang W: Quality of life for children with fecal incontinence after surgically corrected anorectal malformation. J Pediatr Surg 35: 462-464, 2000.

5. Rintala RJ and Lindahl $\mathrm{H}$ : Is normal bowel function possible after repair of intermediate and high anorectal malformations? J Pediatr Surg 30: 491-494, 1995.

6. Froster UG, Wallner SJ, Reusche E, Schwinger E and Rehder H: VACTERL with hydrocephalus and branchial arch defects: Prenatal, clinical, and autopsy findings in two brothers. Am J Med Genet 62: 169-172, 1996.

7. Levin MD: The pathological physiology of the anorectal defects, from the new concept to the new treatment. Eksp Klin Gastroenterol 11: 38-48, 2013 (In Russian).

8. Li L, Li Z, Wang LY and Xiao FD: Anorectal anomaly: Neuropathological changes in the sacral spinal cord. J Pediatr Surg 28: 880-885, 1993.

9. Yuan Z, Bai Y, Zhang Z, Ji S, Li Z and Wang W: Neural electrophysiological studies on the external anal sphincter in children with anorectal malformation. J Pediatr Surg 35: 1052-1057, 2000.

10. Fernández-Fraga X, Azpiroz F and Malagelada JR: Significance of pelvic floor muscles in anal incontinence. Gastroenterology 123 : 1441-1450, 2002.

11. Mulè F, Naccari D and Serio R: Evidence for the presence of $P 2_{Y}$ and $\mathrm{P} 2 \mathrm{x}$ receptors with different functions in mouse stomach. Eur J Pharmacol 513: 135-140, 2005.

12. Arthur DB, Akassoglou K and Insel PA: P2Y2 receptor activates nerve growth actor/TrkA signaling to enhance neuronal differentiation. Proc Natl Acad Sci USA 102: 19138-19143, 2005.

13. Liu Y, Kong M, Jin Z, Gao M, Qu Y and Zheng Z: Expression of the P2Y2 receptor in the terminal rectum of fetal rats with anorectal malformation. Int J Clin Exp Med 8: 1669-1676, 2015.

14. Nasser Y, Fernandez E, Keenan CM, Ho W, Oland LD, Tibbles LA, Schemann M, MacNaughton W, Anne R and Sharkey KA: Role of enteric glia in intestinal physiology: Effects of the gliotoxin fluorocitrate on motor and secretory function. Am J Physiol Gastrointest Liver Physiol 291: G912-G927, 2006.

15. Hinman MN and Lou $\mathrm{H}$ : Diverse molecular functions of $\mathrm{Hu}$ proteins. Cell Mol Life Sci 65: 3168-3181, 2008.

16. Bolognani F, Merhege MA, Twiss J and Perrone-Bizzozero NI: Dendritic localization of the RNA-binding protein HuD in hippocampal neurous: Association with polysomes and upregulation during contextual learning. Neurosci Lett 371: 152-157, 2004.

17. Deschenes-Furry J, Belanger G, Perrone-Bizzozero $\mathrm{N}$ and Jasmin BJ: Post-transcriptional regulation of acetylcholinesterase mRNAs in nerve growth factor-treated PC12 cells by the RNA-binding protein HuD. J Biol Chem 278: 5710-5717, 2003.

18. Kong M, Wu Y and Liu Y: The impact of HuD protein on the intestinal nervous system in the terminal rectum of animal models of congenital anorectal malformation. Mol Med Rep 16: 4797-4802, 2017.

19. Abdelmohsen K, Hutchison ER, Lee EK, Kuwano Y, Kim MM, Masuda K, Srikantan S, Subaran SS, Marasa BS, Mattson MP and Gorospe M: miR-375 inhibits differentiation of neurites by lowering HuD levels. Mol Cell Biol 30: 4197-4210, 2010.

20. Mandhan P, Quan QB, Beasley S and Sullivan M: Sonic hedgehog, BMP4 and Hox genes in the development of anorectal malformations in ethylenethiourea-exposed fetal rats. J Pediatr Surg 41: 2041-2045, 2006.
21. Livak KJ and Schmittgen TD: Analysis of relative gene expression data using real-time quantitative PCR and the 2(-Delta Delta C(T) ) method. Methods 25: 402-408, 2001.

22. Young HM: Functional development of the enteric nervous system-from migration to motility. Neurogastroenterol Motil 20 (Suppl 1): S20-S31, 2008

23. Lake JI and Heuckeroth RO: Enteric nervous system development: Migration, differentiation, and disease. Am J Physiol Gastrointest Liver Physiol 305: G1-G24, 2013.

24. Kapur RP, Yost C and Palmiter RD: A transgenic model for studying development of the enteric nervous system in normal and aganglionic mice. Development 116: 167-175, 1992.

25. Fu M, Lui VC, Sham MH, Cheung AN and Tam PK: HOXB5 expression is spatially and temporarily regulated in human embryonic gut during neural crest cell colonization and differentiation of enteric neuroblasts. Dev Dyn 228: 1-10, 2003.

26. Fu M, Tam PK, Sham MH and Lui VC: Embryonic development of the ganglion plexuses and the concentric layer structure of human gut: A topographical study. Anat Embryol (Berl) 208: 33-41, 2004

27. Jiang Y, Liu M and Gershon MD: Netrins and DCC in the guidance of migrating neural crest-derived cells in the developing bowel and pancreas. Dev Biol 258: 364-384, 2003.

28. Flores RV, Hernández-Pérez MG, Aquino E, Garrad RC, Weisman GA and Gonzalez FA: Agonist-induced phosphorylation and desensitization of the P2Y2 nucleotide receptor. Mol Cell Biochem 280: 35-45, 2005.

29. Brandenburg LO, Jansen S, Wruck CJ, Lucius R and Pufe T: Antimicrobial peptide rCRAMP induced glial cell activation through P2Y receptor signalling pathways. Mol Immunol 47: 1905-1913, 2010.

30. Kong Q, Peterson TS, Baker O, Stanley E, Camden J, Seye CI, Erb L, Simonyi A, Wood WG, Sun GY and Weisman GA: Interleukin-1beta enhances nucleotide-induced and $\alpha$-secretase-dependent amyloid precursor protein processing in rat primary cortical neurons via up-regulation of the $\mathrm{P} 2 \mathrm{Y}(2)$ receptor. J Neurochem 109: 1300-1310, 2009.

31. Degagné E, Grbic DM, Dupuis AA, Lavoie EG, Langlois C, Jain N, Weisman GA, Sévigny J and Gendron FP: P2Y2 receptor transcription is increased by NF-kappa B and stimulates cyclooxygenase-2 expression and PGE2 released by intestinal epithelial cells. J Immunol 183: 4521-4529, 2009.

32. Wullaert A, Bonnet MC and Pasparakis M: NF- $\mathrm{BB}$ in the regulation of epithelial homeostasis and inflammation. Cell Res 21 : 146-158, 2011.

33. Agresti C, Meomartini ME, Amadio S, Ambrosini E, Volonté C, Aloisi $\mathrm{F}$ and Visentin S. ATP regulates oligodendrocyte progenitor migration, proliferation, and differentiation: Involvement of etabotropic P2 receptor. Brain Res Brain Res Rev 48: 157-165, 2005.

34. Weisman GA, Camden JM, Peterson TS, Ajit DV, Woods LT and Erb L: P2 receptors for extracellular nucleotides in the central nervous system: Role of $\mathrm{P} 2 \mathrm{X} 7$ and $\mathrm{P} 2 \mathrm{Y}_{2}$ Receptor Interactions in neuroinflammation. Mol Neurobiol 46: 96-113, 2012.

35. Hayashi S, Yano M, Igarashi M, Okano $\mathrm{HJ}$ and Okano $\mathrm{H}$ : Alternative role of $\mathrm{HuD}$ splicing variants in neuronal differentiation. J Neurosci Res 93: 399-409, 2015.

36. Evangelisti C, Bianco F, Pradella LM, Puliti A, Goldoni A, Sbrana I, Rossi M, Vargiolu M, Seri M, Romeo G, et al: Apolipoprotein $\mathrm{B}$ is a new target of the GDNF/RET and ET-3/EDNRB signalling pathways. Neurogastroenterol Motil 24: e497-e508, 2012.

37. Yang X, Wen G, Tuo B, Zhang F, Wan H, He J, Yang S and Dong H: Molecular mechanisms of calcium signaling in the modulation of small intestinal ion transports and bicarbonate secretion. Oncotarget 9: 3727-3740, 2017.

This work is licensed under a Creative Commons Attribution-NonCommercial-NoDerivatives 4.0 International (CC BY-NC-ND 4.0) License. 